\title{
Organisational Factors, the Last Frontier?
}

\author{
Ivan Boissières
}

\begin{abstract}
Significant advances have been made in the field of human and organisational factors (HOF) integration in industrial groups these last decades. Nowadays, HOF are generally quite structured in companies, in the form of a coalition between a few key departments and their allies. Nevertheless, various features limit their scope, notably in their impact on the organisation. First, we must acknowledge that the 'o' in Human and organisational Factors is a small 'o'. What lies behind this statement is that the human factors approach dominates, and the purely organisational approach is given far less attention. Then the various approaches usually remain limited to safety issues. HOF issues are rarely considered in strategic trade-offs, or in restructuring or management discussions. Finally, since the success of HOF implementation is mostly built on the political will and relationships of a few key individuals with top managers, they usually do not persist when these people leave. Beyond these observations, this chapter, based on a solid experience of HOF approaches that have been implemented since the 2000s in different industrial sectors, explores the underlying reasons for these limitations and proposes some ways forward for a better integration and sustainability of HOF in high-risk companies.
\end{abstract}

Keywords Organisational factors $\cdot$ HOF coalition $\cdot$ HOF supply

\section{Introduction: Human and Organisational Factors with a Small "O”' (HoF)}

Many high-risk companies often present the incorporation of human and organisational factors (HOF) as the last step in their safety strategy, after having first taken essentially technical then procedural measures.

There is no doubt that this approach has allowed progress to be made in the dissemination of the major concepts illustrating the human contribution to safety. For example, there is a growing acceptance of the difference between work as done

\footnotetext{
I. Boissières $(\bowtie)$

Icsi, Toulouse, France

e-mail: Ivan.Boissieres@icsi-eu.org

(C) The Author(s) 2020

B. Journé et al. (eds.), Human and Organisational Factors,

SpringerBriefs in Safety Management,

https://doi.org/10.1007/978-3-030-25639-5_7
} 
and work as imagined. Many companies are considering the importance of managed safety as a complement to rule-based safety and this tends to be reflected in their structuring of human and organisational factors.

However, some practices are struggling to truly evolve:

- Major reorganisations are still essentially technocratic and their impact on work groups and safety is rarely anticipated.

- Beyond awareness campaigns with little or no follow-up, it is very difficult to invest in HOF skills for operational managers.

- Leadership from company executives is affected by a high turn-over rate, thus undermining continuity in terms of HOF approaches.

- Safety is still only marginally integrated into the organisation's key processes (design, human resources, finances, etc.). Therefore, its place in the strategic decision-making process can be seriously weakened when the company is experiencing financial turbulence.

On closer examination, these limitations seem to be concentrated around organisational factors in the broad sense. Could it be that the term HOF actually hides different realities? It must be acknowledged that the 'o' in human and organisational factors often is a small ' $\mathrm{o}$ '. On the one hand there is the progress made by the human factors approach, which focuses closely on workers and the reality in the field. On the other hand, it seems to be more difficult to change the organisation and managerial practices.

We propose to examine this hypothesis in more depth, based on experience of HOF approaches implemented since the 2000 s in high-risk companies. ${ }^{1}$ We will more specifically explore potential causes of this blockage not on the demand side (resistance of organisations to change their practices), but rather on the HOF supply side. Are the experts' profiles relevant? Are there difficulties in appropriating fields mostly peopled by general consultants and gurus and considered to be scientifically weak? Is the HOF "coalition" powerful enough to allow an actual consideration of HOF in companies?

\section{Is the Role of Organisational Factors in the HOF Domain Actually a Problem of Supply?}

One of the main reasons why it is so difficult to fully take organisational issues into account might be the profile of HOF suppliers, who are nearly all psychologists and ergonomists, to the detriment of sociologists and management scientists. We truly owe a lot to this community for raising the profile of human factors in companies.

\footnotetext{
${ }^{1}$ This chapter is above all based on a personal experience of consideration of HOF in companies: first as a Ph.D. fellow, then as an operational manager in a foreign subsidiary, and as an internal or external adviser to the executive management of large French groups, in various sectors: telecommunications, energy, transports, construction... Therefore, it may not be exempt from some overgeneralizations or caricatures.
} 
However, consideration of organisational factors seems to be limited by some of their specificities such as the areas they choose to work in, their relationship to management, or even the theoretical framework.

The domains where human factors are considered relevant have changed greatly. The focus has moved from operator protection, to optimizing their work, safety and performance. There seems to be a desire to slowly 'climb' from the micro (the work situation) to more macro dimensions related to the organisation of work. This has been most successful in the field of the design (of a workstation or a factory). But it has very rarely been used to address large-scale managerial or organisational change.

An organisational intervention also means changing who HOF specialists talk to. Historically, they have been invited in by departments that are doing quite similar work, such as the medical service or internal ergonomists. They also have interacted a lot with front-line managers, i.e. the production or design team at the factory or project level. Working on the organisation and major strategic decisions involves a shift from the production line to the management line, or even to the level of general management [2]. This represents a jump that is often difficult for HOF specialists to make because they do not want to lose their credibility with workers in the field or to be manipulated due to lack of leeway.

Finally, organisational factors appear to be a domain that is reserved for another category of stakeholders - auditors and management consultants. The business world is, in some ways, implicitly divided in two. Human factors approaches apply to working conditions (workers, safety, design) while auditors or management consultants work on organisational problems, management and strategic decisions. It is apparently difficult to overcome this division because, on the one hand, the human factors community is very critical of the lack of scientific knowledge of management consultants and of some so-called gurus. On the other hand, not many of these experts are interested in safety issues. There do not seem to be many bridges between the two worlds, especially since organisational sociologists-whose work is closer to the ideas of human and organisational factors-have almost disappeared from companies. In the nineties, it was common to find sociologists working at the top level in companies such as Air France, RATP, Danone, Michelin, etc. As an example, during my PhD at France Telecom, I worked with a sociologist who advised the general management to support the reorganisation of one of its departments [4]. Nowadays, the demand from companies for sociological support is so low, it is hardly possible to quote such an example $[6,8]$. The lack of development of organisational aspects in HOF approaches is harmful because it risks locking those approaches into an overly-limited view of the problem. Above all, rather like a 'glass ceiling', it might block access to the level where solutions can most often be found: organisational, management or strategic decisions. 


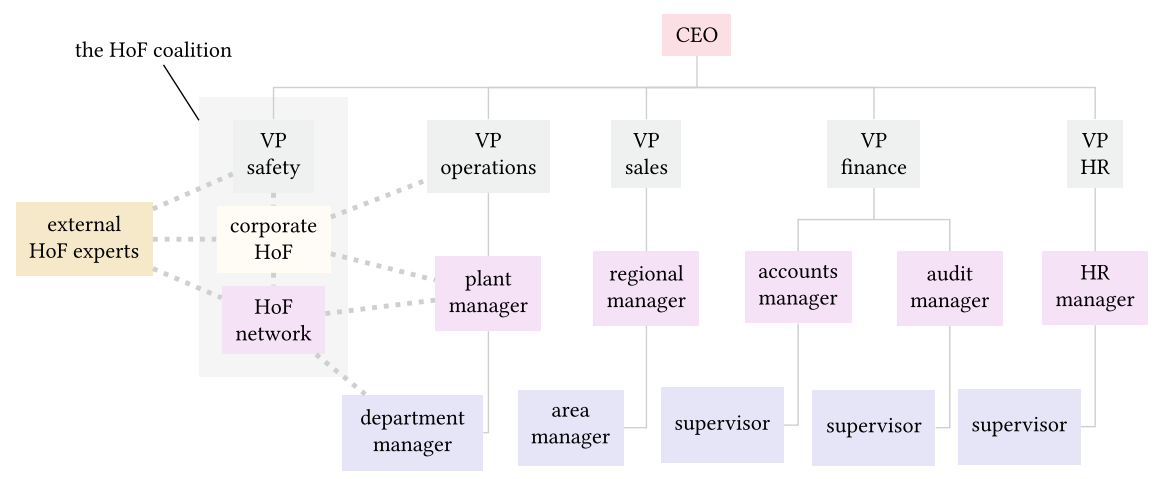

Fig. 1 The HOF 'coalition': the current situation

\section{The Current HOF "Coalition"}

How is the HOF approach currently structured in at-risk companies in France? Who are the key actors, the members of the coalition that is driving progress? Where are they located in the organisation?

First, we will address the external options the French HOF market has to offer. As already stated in this chapter, the supply is mostly composed of experts with experience in human factors and ergonomics, working in small consulting companies. This community is well-structured; its members are part of an association, the SELF (The Society of French-speaking Ergonomists) and they regularly meet to share their experience. In fact, there are many more of these external consultants than internal experts.

Secondly, what are the current trends within companies? Based on experience with several large industrial groups, some conclusions can be drawn (Fig. 1).

Some at-risk companies have centralised their HOF expertise. It may be the responsibility of a single person, usually a former consultant, or an $\mathrm{HSE}^{2}$ employee who has specialized in human and organisational factors. At best, it is a department combining these profiles. In any case, it is a very lightweight structure that aims to promote HOF approaches or to capitalize on local experiments in order to disseminate them. It can also be supported by an R\&D department staffed by HOF researchers.

In some leading companies, there might be HOF specialists posted in the field. In some cases, they have organised themselves into a network. For example, at the French national railway company $\left(\mathrm{SNCF}^{3}\right)$ or in the nuclear sector, there are human factors consultants. But the relationship between headquarters and this decentralised network is not always easy. On-site experts work closely with their colleagues and

\footnotetext{
${ }^{2}$ Health, Safety and Environment.

${ }^{3}$ Société nationale des chemins de fer français.
} 
have more in common with local managers than with a centralised HOF unit. Sometimes, they do not even belong to the same sector. At SNCF, for instance, the human factors network is part of the human resources department and mainly deals with the quality of life at work and occupational safety. Meanwhile, in the same company, the central HOF department is part of the industrial safety division!

In the vast majority of cases, HOF falls within the remit of HSE structures, or those responsible for major risks. For example, at Air France, the HOF unit is part of flight safety. At SNCF it is part of railway safety, and at $\mathrm{EDF}^{4}$ a French electric utility company, of nuclear safety.

Finally, this small internal network, which is often somewhat disconnected, takes its orders from a few decision makers who are convinced that the HOF approach can help them solve their operational problems. However, these managers are still very much in the minority, which generally leads to ad hoc requests. The Institute for an industrial safety culture (Icsi), created in 2003 following the AZF accident in Toulouse (France), promotes a collective dynamic which allowed to launch large safety culture reinforcement programmes based on better consideration of HOF. However, although these approaches are often initiated by top managers, they appear difficult to maintain in the long-term when these managers change positions or leave the company.

\section{Proposals for Ways Forward}

To overcome some of the limitations described above and reinforce the HOF coalition so that it can work on organisational issues, here are a few ideas based on our experience working with industrial companies.

\subsection{Managers/Senior Executive Staff: Reaching a Critical Mass}

The first suggestion regards the relationship between HOFs and top managers. Connecting these two "worlds" is not easy because many top managers just have a few vague ideas about HOF or have developed their own way of doing things. Typically, they see the organisation as a structure only, or a set of rules and procedures where top-down management and little participation from the employees prevail. They do not really consider the impact on teams or power struggles as they implement changes in the organisation.

This is exactly why HOF experts need to talk to the top managers. At the very least, this reconciliation would allow them to share the basis of a common vision and overcome some stereotypes. This should help to avoid misunderstandings or failures.

\footnotetext{
${ }^{4}$ Electricité de France.
} 
Thus, the challenge is to build a critical mass of top managers who are open to the HOF approach, rather than have a few lonely evangelists within the organisation. Moreover, it is of importance that HOFs do not remain enclosed within the safety department, because there is a risk of disconnection from the organisation's other strategic challenges.

\subsubsection{Training: HOF as a Dimension of Management and not as a Standalone Topic}

Training plays a key role in the integration of HOF in companies, and there are certain conditions that might foster success. In France, at least two training programmes had a significant impact on HOF in the industry.

\section{Icsi}

In 2005, Icsi and François Daniellou launched a 2-day training programme on HOF. This has proved successful since over 300 professionals attended it, creating demand for an executive master in HOF in partnership with ESCP Europe Business School. To date, more than 150 managers have studied for this master's degree (https://www.escpeurope.eu/programmes/executive-masters/executivemastere-specialise-manager-des-organisations-a-risques). Unfortunately, participants mainly consisted of HSE specialists and very few were senior managers or Executive Committee members.

\section{CEDEP $^{5}$}

Another training programme delivered by CEDEP is specifically targeted at Executive Committee members of Sanofi and L'Oréal. This programme is very successful and HSE specialists are not the majority of participants. However, it does not meet HOF standards. The training session starts with leadership, organisational culture and change management, and safety is addressed only much later.

These examples illustrate how difficult it is to get operational managers to attend HOF training. It also shows that a promising avenue is to integrate HOF into managerial training programmes instead of asking managers to attend specific HOF sessions. Moreover, one of the conclusions of the strategic analysis carried out by FonCSI $^{6}$ on professionalism is that safety should be better integrated into professional development rather than being taught separately $[3,7]$.

The best way to reach top management is with specially designed, internal training programmes.

\footnotetext{
${ }^{5}$ The Executive Education department of the INSEAD business school (European Institute of Business Administration).

${ }^{6}$ Foundation for an industrial safety culture.
} 
“HSE for Senior Executives" and "HSE for Managers”, Total

From 2011, Total launched 2-4-day training programmes targeting senior top executives and managers, respectively. The whole top management stratus is required to follow this course that is based on a 360-degree assessment of safety leadership and solid face-to-face training in $\mathrm{HOF}$, followed by regular coaching.

\section{Vinci Construction}

More recently, Vinci Construction developed a one-and-a-half-day internal training programme called "Managing Through Safety", with a significant focus on HOF. It is part of "Cap for Management", the general, 6-day training programme for Vinci managers. It covers the fundamentals of management: finance, HR, business, innovation, etc. Even though the top executives stay for just a day and a half, the part they attend is dedicated to safety.

\subsection{2 ...so that Managers' Vision and Practices Can Evolve}

The integration of HOF to other managerial challenges implies that current HOF specialists should be receptive to general management topics like power relations, corporate culture, leadership, change management, etc. It also involves encouraging more leadership or change management specialists to take an interest in safety. And, finally, it means that the topic should be included in internal management training courses, and externally by getting business schools to offer HOF training.

The real challenge is not to improve the marketing of HOF training programmes for managers. Above all, the objective is to profoundly change the attitudes of managers and management models that often represent an obstacle to giving proper consideration to HOF in companies.

\subsubsection{Open up HOF Networks to Operational Managers}

We stated earlier that decentralized HOF networks are sometimes found in companies with on-site internal consultants, or in business divisions. But they are usually made up of HOF specialists with a background in ergonomics and they find it difficult to influence important decisions since managers do not recognize their operational competence. Attracting more operational managers to HOF courses strengthens HOF networks by benefiting from their business profile.

\section{EDF}

At EDF, human factor consultants working in nuclear plants now operate in pairs made up of an external human factors expert or ergonomist, and someone else with operational experience and solid training in HOF. 


\section{SNCF Traction}

Each year, 2-3 executives from SNCF traction, the train driver division, complete the Icsi executive master's degree in HOF. Over time, this has created an internal HOF network of operational staff. Today, SNCF Traction is one of the places where most progress has been made in HOF-both at the SNCF level and at the level of French industry. This was made possible thanks to a director who is a leader in the domain, and the network that played a determining role in driving the deployment of HOF initiatives internally.

\subsection{Strengthen Alliances with Other Actors}

Safety is not the only risk that businesses must manage. Production is fundamental too-and HOF specialists have a long history of talking to engineering firms about the technical details of projects in order to anticipate operational risks. Furthermore, a poor social climate and financial problems are other major risks that threaten the company's survival. If HOF is going to play a role in the company's trade-offs, it must be better integrated into the other departments concerned.

\subsubsection{Human Resources Department}

An alliance with the human resources department seems easiest, probably because this is where there are most bridges with safety and HOF.

Psychosocial risk issues are now being closely monitored by human resources departments, often with the support of experts. It is now accepted that the root causes of psychosocial risks are embedded in the organisation and management. Adopting this angle of attack would not only mobilize human and organisational factors but would do it by means of a topic linked to the organisation.

Some other issues interface easily with human resources, one of which is training. We already highlighted the importance of managers training in HOF. Indeed, it helps to get closer to human resources departments and allows a collaborative work on the evolution of the management model that will serve as a basis for internal or external training.

Another example of topics at the interface with human and organisational factors is "just culture". When translated at the level of an organisation, "just culture" is about drawing up clear and fair policies in terms of recognition of good practices/sanction of bad practices. Typically, it falls within the domain of human resources, but it is also very fashionable in the safety world at the moment [5]. 


\subsubsection{Audit Departments}

When it comes to investment decisions, any alliances must eventually extend to other influential departments such as compliance and audit departments. This process is just starting. As an example, a renowned human factors expert recently took part in an audit and regulatory review [1]. Conversely, for the first time a financial controller attended the Icsi HOF executive master in 2018.

\subsubsection{Trade Unions/Regulatory Authorities}

In addition to the managerial chain of command and internal managers, two other institutional actors, union and staff representatives and regulatory authorities may be effective partners.

Providing union representatives with HOF training represents a valuable investment because it creates internal pressure for organisational factors to be considered at a very high level. A major French trade union, CFDT, and more specifically its chemical energy federation, has created a major risks network and have taken HOF to heart. They trained themselves and drew up internal policies on safety topics which have been distributed to staff committees on all sites. Their influence has led to real progress.

\section{Exxon Mobil-CFDT}

CFDT representatives at a large Exxon Mobil site asked for a safety culture survey to be carried out. The analysis of this assessment led to the creation of a working group that brought together directors, the local chemistry federation, regional officials, union representatives, regulatory authorities, etc. It is not common to have such diverse actors at the same table. It generated a discussion of great interest, at a very high level, about how each organisation could help to improve industrial safety based on HOFs.

Finally, regulatory authorities are another solid ally that can, if needed, put moreor-less friendly pressure on company managers to consider HOF. The influence of international authorities in aeronautics is addressed in this book (see Florence Reuzeau's chapter, this volume). In the nuclear sector, the authority is carrying out fundamental work into human and organisational factors on various topics including industrial policy and subcontracting. There has not been any strong commitment so far, but it has, at least, forced the various stakeholders in the French nuclear sector to ask questions and eventually to agree on the way forward. 


\section{Concluding Remarks: Use Short-Term Wins to Sustain Long-Term Progress}

It must be recognized, of course, that the different propositions discussed in this chapter are difficult to implement. Therefore, it is of paramount importance to establish a strategy for implementing HOF over a longer timeframe. Like any project that seeks to implement change, a two-step approach is needed: quick wins and long-term structured action.

\subsection{In the Short Term: HOF Quick Wins}

Before going any further, HOF must be put on the agenda and win in the short term. Here follow a few examples of quick win initiatives. A conference or a training session for directors conducted by an excellent speaker, is an efficient way of stimulating interest in going further. Similarly, videos or e-learning courses are good ways to introduce the topic.

\section{E-learning}

Icsi recently developed a short, e-learning module intended for directors and managers of a large industrial group to raise awareness about HOF. This was rapidly followed by further training for prevention specialists and managers at a local site, and a request from the CEO for a HOF study.

A safety culture assessment is another good way to open the door to more advanced HOF approaches - notably as it speaks to managers who love indicators. The starting point is safety issues, but it can go on to highlight organisational causes, such as managerial leadership, or reward and sanction policies. The most important aspect is that the clients should be management committees and not limited to safety managers.

These approaches are sometimes criticized by purists on the pretext that they are not ambitious enough, or that they tell the client only what they want to hear. However, considering them as a first step, they can be an effective way to get a foot in the door. Once you have done that, HOF approaches can be developed and implemented over time.

\subsection{Anchoring HOFs in Companies: Key Actions}

The actual issue at stake is to institutionalize HOF approaches in companies, especially in terms of organisational and strategic processes. Companies should seize opportunities related to specific moments of their life: some steps can be particularly 
conducive to launching a HOF approach. One interesting example is to integrate safety and HOF issues when the company is planning a major restructuring. Another opportunity is the implementation of a policy of formalizing the skills managers are expected to have. As an example, Suez has drawn up a guide for managers where principles like "the right to make mistakes" and the need to recognize the contribution of workers are made clear.

In a nutshell, integration and sustainability of HOF approaches in high-risk companies mostly rely on going beyond the glass ceiling by reaching a critical mass of executives open to HOF concepts, reinforcing alliances with other key sectors such as human resources, unions and regulatory bodies, and capitalizing on quick wins to sustain long-term progress.

\section{References}

1. R. Amalberti, La sécurité industrielle est-elle un art du compromis? Audit, risques et contrôle (12), 25-28 (2017), https://www.foncsi.org/fr/blog/article-a-r-c-rene-amalberti

2. R. Amalberti, F. Mosneron-Dupin, Facteurs humains et fiabilité: quelles démarches pratiques (Octares, Toulouse, 1997)

3. C. Bieder, C. Gilbert, B. Journé, H. Laroche, Beyond Safety Training: Embedding Safety in Professionnals Skills (Springer, 2017). https://doi.org/10.1007/978-3-319-65527-7

4. I. Boissières, Une approche sociologique de la robustesse organisationnelle: le cas du travail des réparateurs sur un grand réseau de télécommunication. Doctoral dissertation, Université de Toulouse 2, Toulouse (2005)

5. S. Dekker, Just Culture: Balancing Safety and Accountability (Ashgate, 2012)

6. F. Dupuy, La Faillite de la pensée managériale. Lost in Management, vol. 2 (Seuil, Paris, 2015)

7. FonCSI, La sécurité, une affaire de professionnels ? Intégrer la sécurité aux compétences professionnelles. Fondation pour une culture de sécurité industrielle (Foncsi, Toulouse, France, 2018), https://www.foncsi.org/fr/publications/collections/cahiers-securite-industrielle/securiteaffaire-professionnels

8. La sociologie sur commandes?, Sociologies pratiques (36) (2018)

Open Access This chapter is licensed under the terms of the Creative Commons Attribution 4.0 International License (http://creativecommons.org/licenses/by/4.0/), which permits use, sharing, adaptation, distribution and reproduction in any medium or format, as long as you give appropriate credit to the original author(s) and the source, provide a link to the Creative Commons license and indicate if changes were made.

The images or other third party material in this chapter are included in the chapter's Creative Commons license, unless indicated otherwise in a credit line to the material. If material is not included in the chapter's Creative Commons license and your intended use is not permitted by statutory regulation or exceeds the permitted use, you will need to obtain permission directly from the copyright holder.

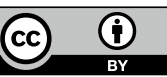

